\title{
Organization of the Organization
}

A brief account of three aspects of organization at CERN, covering: - the Council and its associated committees

- the new internal organization

- the process of selection for the experimental programmes at the accelerators.

\section{The Council}

The supreme body governing the affairs of CERN is the Council, made up of two delegates from each Member State, who may be accompagnied by advisers. Each State has one vote in Council which it may exercise in all matters where it has a financial stake. In addition to being the governing body of the Organization, the Council Members and their advisers, and the Members of the other Council Committees - the Scientific Policy Committee and the Finance Committee (q.v.) constitute important links with the authorities in the Member States. Heading the Council is the president - Dr. G. W. Funke - who is elected with two vice-presidents for one year but may be re-elected in succeeding years up to maximum of three consecutively.

It is for the Council to agree upon the broad lines of research policy and match these with adequate resources in money and manpower. It is charged by the Convention with adopting the budget, reviewing expenditure and publishing the audited accounts of the Organization. The Council must also approve the Staff Rules, the Financial Rules and the Rules of the Pension Fund, which provide the main framework of administrative policy.

The Committee of Council, which now consists of one member per State together with the Chairmen of the Scientific Policy Committee, the European Committee for Future Accelerators and the Finance Committee, has been specifically charged by the Council with the work preparatory to Council decisions on the $300 \mathrm{GeV}$ project, including the revision of the Convention and the selection of the site. Member States have already expressed the view

Figure 1: The CERN Council and its associated committees. that both Laboratories should be part of a single organization and that the present Convention should be adapted to accommodate the expansion.

Two permanent committees give specialist advice to the Council; one on scientific policy and the other on financial matters. The need for the Finance Committee (current chairman Dr.W. Schulte-Meermann) was specifically presaged in the Financial Protocol to the Convention.

It is the Finance Committee (FC) that receives the budget and reports on it to Council, whilst at the same time it decides on the form in which CERN's own accounts should be rendered. In day-to-day affairs it must be notified of significant transfer of funds inside the budget and given prior notice of any operations which would involve an excess over the budget. One of its more important tasks is to approve the major contracts (over SFr. 750 000) that are let to industry by CERN, ensuring that these are placed at the lowest tender figure provided always this is consistent with the technical requirements being satistied.
The Scientific Policy Committee (SPC) presently chaired by Prof. G. Puppi is made up of eminent scientists, chosen in their own right rather than as representatives of a specific State. Its prime activity is to provide Council with the best possible advice on scientific developments and their implications to the organization.

Quite separate is the European Committee for Future Accelerators (ECFA) which was first set up in January 1963 jointly by the Director General (D. G.) and the Chairman of the SPC following the Council meeting the previous month. A wide representation of European physicists was sought under the chairmanship of Professor Amaldi and the result of their deliberations was a report which was passed to the SPC and which made far reaching recommendations as to the new policies and machines needed in Europe including for example the ISR project.

At the beginning of last year ECFA was again reconvened and the Council at its meeting in June this year will be considering a second report which will bring up to date the views of the Committee on

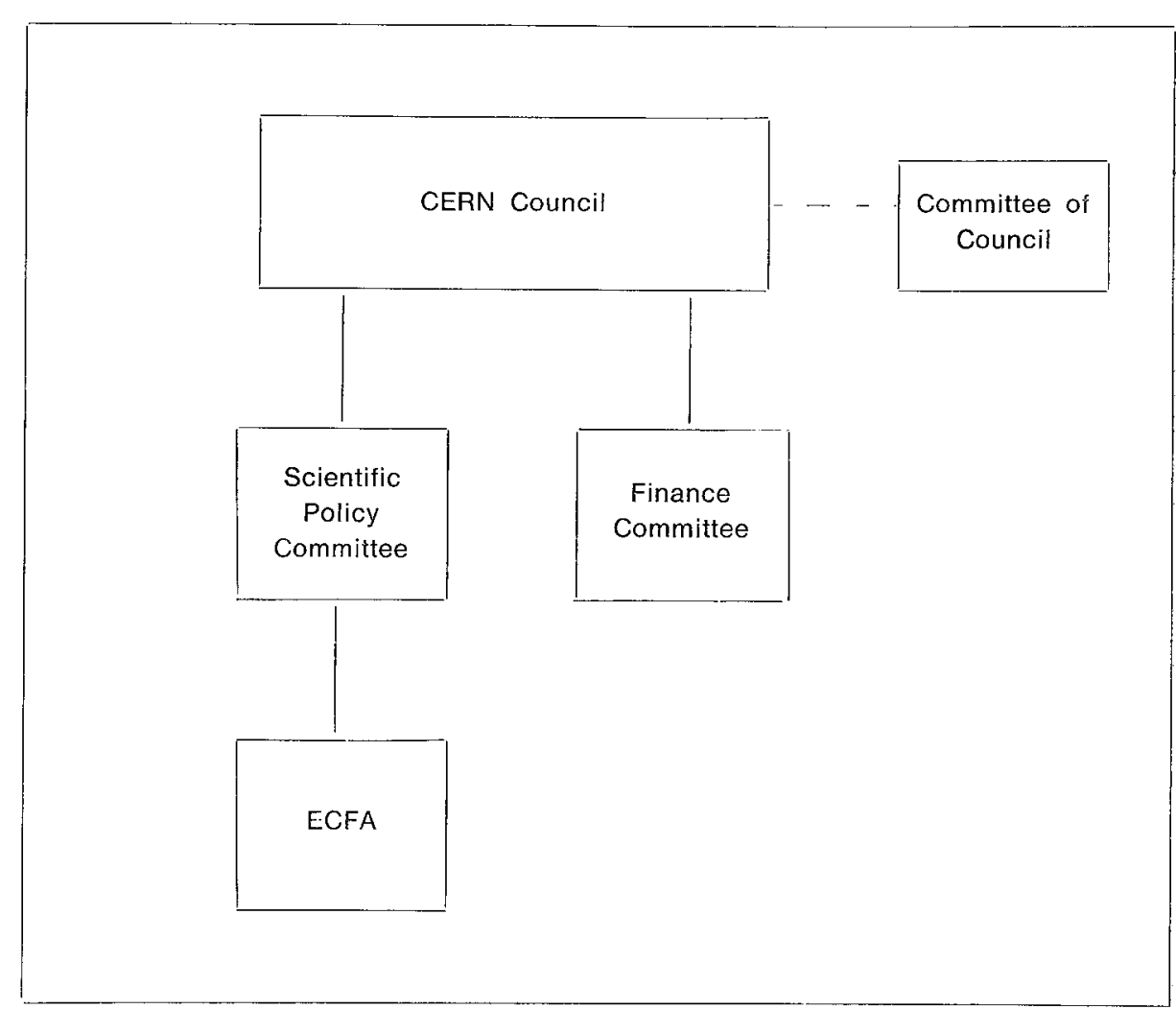




\begin{tabular}{|c|c|c|c|c|c|}
\hline & & $\begin{array}{l}\text { Physics II } \\
\text { Department }\end{array}$ & $\begin{array}{l}\text { Theoretical } \\
\text { Physics } \\
\text { Department }\end{array}$ & \multicolumn{2}{|c|}{$\begin{array}{l}\text { Proton Synchrotron } \\
\text { Department }\end{array}$} \\
\hline $\begin{array}{c}\text { Nuclear } \\
\text { Physics } \\
\text { Division } \\
\text { (NP) }\end{array}$ & $\begin{array}{c}\text { Synchro- } \\
\text { cyclotron } \\
\text { Machine } \\
\text { Division } \\
\text { (MSC) }\end{array}$ & $\begin{array}{c}\text { Track } \\
\text { Chambers } \\
\text { Division } \\
\text { (TC) }\end{array}$ & $\begin{array}{l}\text { Theoretical } \\
\text { Studies } \\
\text { Division } \\
\text { (TH) }\end{array}$ & $\begin{array}{l}\text { Proton } \\
\text { synchrotron } \\
\text { Machine } \\
\text { Division } \\
\text { (MPS) }\end{array}$ & $\begin{array}{l}\text { Nuclear } \\
\text { Physics } \\
\text { Apparatus } \\
\text { Division } \\
\text { (NPA) }\end{array}$ \\
\hline
\end{tabular}

the status and needs of high energy physics in Europe today.

\section{Internal organization}

Following the proposal of the Director General, Professor Gregory, the Council adopted a new internal organization for CERN at its session in June 1966.

One of the main features of the organization is the substitution of seven Departmental directors for the four members of the Directorate: two for experimental physics, one for theoretical physics, one for the proton synchrotron, one for applied physics, one for construction of the intersecting storage rings and one for administration. The Directors and the Director General form a Board of Directors which deals with important problems relating to the running of CERN.

All CERN's work is regrouped in seven Departments. The Departmental Directors are appointed for fixed terms and their functions are twofold: they are directly responsible for running their Departments and they help form policy in the Board of Directors.
The Departments are as follows: 1) Physics I, Director: Professor Wolfgang Paul

This Department includes two previously existing Divisions, Nuclear Physics (NP) and Synchro-cyclotron (MSC).

The main task of the Nuclear Physics Division (Leader, Professor P. Preiswerk) remains the carrying out, in collaboration with European universities and Laboratories, of the high energy physics programme at the proton synchrotron and the synchrocyclotron, using counter and nuclear emulsion techniques. All work done at the synchro-cyclotron, a large part of which concerns research on nuclear structure, now comes under this Department. In addition, the Division is responsible for the design and operation of the beams needed for these experiments and for developing the equipment necessary for research with them.

The MSC Division (Leader, Dr. G. Brianti) is responsible for the work in connection with the operation, maintenance and development of the $600 \mathrm{MeV}$ synchrocyclotron.
2) Physics 1I, Director: Professor Ch. Peyrou. This Department incorporates the functions of the Track Chambers Division (TC). The decision to establish this as a Department took account of the considerable cevelopment of research in Europe using hydrogen bubble chambers.

The Department is responsible for the operation, maintenance and development of the hydrogen bubble chambers in service at CERN together with the design and operation of particle beams for the chambels; research work using the chambers; continuation of the studies for a very large hydrogen bubble chamber in collaboration with experts from Germany and France. (See CERN COURIER vol. 7, p. 43.)

3) Theoretical Physics, Director: Professor Léon Van Hove.

The work of this Department which incorporates the Theoretical Studies Division with Dr. J. Prentki as Leader, is devoted to pure research in the theory of particle physics. It also maintains close collaboration with the experimental physicists, to assist them in drawing up their programmes and interpreting their results. 


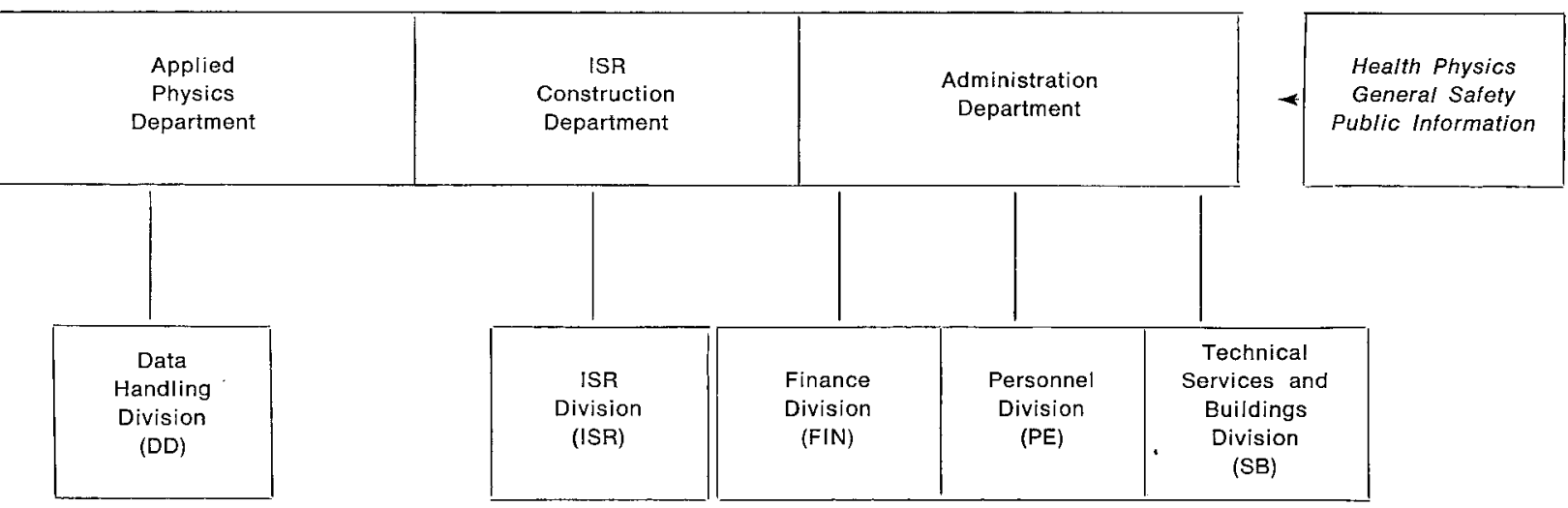

The Theoretical Physics Department is the one at CERN in which more visiting scientists than CERN staff members take part in the work.

4) Proton Synchrotron, Director: Dr. Pierre Germain.

This Department includes the ProtonSynchrotron Division (MPS) and Nuclear Physics Apparatus Division (NPA). The MPS Division (Leader, Dr. P. H. Standley) is responsible for the operation, maintenance and development of the $28 \mathrm{GeV}$ proton synchrotron, including the large improvements programme now under way at the machine.

The NPA Division (Leader, Dr. C.A. Ramm) is responsible for the design and construction of certain equipment necessary for the experimental programme, such as particle separators, the neutrino facilities, etc. It also looks after the operation and development of heavy liquid bubble chambers at CERN and carries out research with these chambers.

5) Applied Physics, Director: Dr. M.G.N. Hine.
This Department includes the Data Handling Division (DD) (Leader, Dr. G. R. Macleod) responsible for the design, construction and operation of equipment for data handling by means of computers. It co-operates closely with the NP and TC Divisions in the experimental programme. The scale of the work done by this Division can be gauged from the fact that CERN has the largest computing centre in Europe. The Department is additionally responsible for much of the forward planning analysis including the preparation of programme costings and is currently heavily engaged upon the $300 \mathrm{GeV}$ project evaluations.

6) ISR Construction, Director: Professor K. Johnsen.

The main task of this Department is to construct the intersecting storage rings which will make possible a new range of experiments using beams taken initially from the PS. In addition, at the present time, the physicists and engineers of the Department are taking part in the studies for the projected European $300 \mathrm{GeV}$ proton synchrotron in collaboration with national study groups.
7) Administration, Director: Mr. G. H. Hampton.

Several Divisions and administrative services are grouped under this Department: Finance (FIN), Leader, Mr. C. Tièche; Personnel (PE), Leader, Mr. G. Ullmann; Technical Services and Buildings (SB), Leader, Mr. H. Laporte and the sections concerned with Health Physics, General Safety and Public Information.

The Director of Administration is also responsible for political relations with the Member States and the host countries (France and Switzerland), Council affairs and relations with other organizations, local communities etc.

To conclude this brief survey of the new internal organization, an Advisory Committee is in being to assist the D. G. which consists of the Departmental Directors, the Division Leaders and a few senior members of the staff. The purpose of this Committee is mainly to provide the CERN management with an overall view of certain general problems. This Committee is designed to improve «horizontal » liaison within CERN. 


\section{Experimental Programme}

Finally, let us take a look at the organization of the selection procedure for the physics experiments - the different ways of bringing experiments which are proposed to the point where they can be carried out at the PS or the SC.

A proposal for an experiment is usually the result of studies and discussions in a European university, a national Laboratory or a CERN group, often in collaboration. When the proposal is sufficiently advanced, generally after long discussions between many people, and an assessment has been made of the financial implications of the project, the time required on one or other of the machines, and the necessary experimental equipment and staff, it is submitted to one of three Physics Committees of CERN. These consist of CERN physicists and representatives of European universities and national Laboratories.

These three Committees, which meet about once a month, are mainly responsible for considering the scientific merit of the proposals. They also make recommendations on the facilities offered by the accelerators in their respective fields.

The scope of the authority of the Committees was originally divided according to the type of experimental equipment to be used in the experiment, but this distribution was partially modified during 1966 . They are now as follows:

Physics I (more commonly called Electronics Experiments Committee) which considers and chooses the proposals for experiments using electronic counters and spark chambers. The Chairman of this Committee is Professor W. Paul (CERN). Physics /I (more commonly called Track Chamber Committee) which considers and selects the proposals for experiments using the bubble chambers at CERN - the $2 \mathrm{~m}$ hydrogen chamber, the $81 \mathrm{~cm}$ hydrogen chamber and the heavy liquid chamber. The Chairman of this Committee is Professor M. Teucher (Federal Republic of Germany).

Physics III (which groups the former Emulsion Experiments Committee and Nuclear Structure Committee) which considers and selects the proposals for experi- ments using nuclear emulsions (the number of these experiments has gradually reduced and they now tend to be more complex) and experiments into nuclear structure (the number of these experiments, particularly using the synchro-cyciotron, has considerably increased in the past few years). For the sake of convenience, this Committee also deals with all proposals for the SC, regardless of the type of equipment concerned. The Chairman of this Committee is Professor A. G. Ekspong (Sweden).

The recommendations of these three Committees are then passed on to the Nuclear Physics Research Committee under the chairmanship of the Director General, which takes the final decisions concerning the experimental programme and the facilities offered by the two accelerators. This Committee has to take into consideration not only the scientific merit of the experiments proposed, but also their technical and financial implications and whether they are compatible with the other experiments in the programme.

The members of the NPRC are the chairmen of the three Committees mentioned above, and representatives of the CERN Departments concerned, viz.: Physics I,
Physics II, Theoretical Physics and Proton Synchrotron Department. These are the directors of these departments and some additional staff members closely involved in the experimental programme. The NPRC meetings are also attended by the PS co-ordinator and, when his presence is needed, by the SC co-ordinator. In addition, a representative of the Rutherford Laboratory is mostly present, and, whenever a senior physicist from Brookhaven is at CERN, he is asked to attend the meetings.

Once the Nuclear Physics Research Committee has approved an experiment or a test aimed at establishing the feasibility of an experiment, the team which generally consists of physicists from national laboratories, European universities and CERN, working in collaboration, can get down seriously to the preparatory work in conjunction with the PS staff responsible for beam lay-outs and other technical facilities. In addition to approving new proposals the Physics Committee and the NPRC regularly review the status and needs of the various experiments in progress. At all stages the Committees seek to further the collaboration between CERN and physicists throughout Europe.

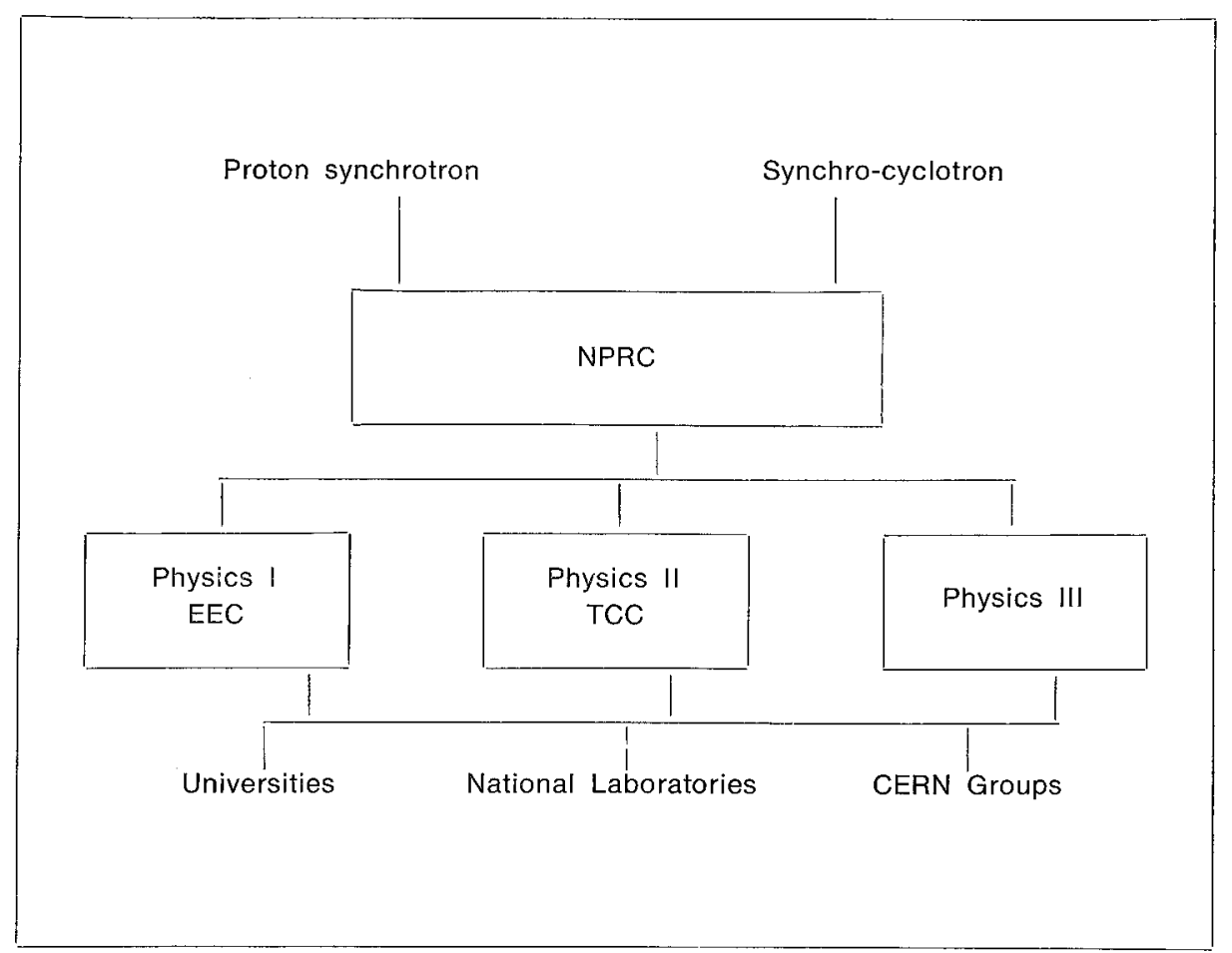

